\title{
Design of Sustainable Biomaterial Composite Adsorbents for Point-of-Use Removal of Lead lons From Water
}

\author{
Mohamed H. Mohamed ${ }^{\dagger}$, Inimfon A. Udoetok ${ }^{\dagger}$, Mostafa Solgi ${ }^{\dagger}$, Bernd G. K. Steiger ${ }^{\dagger}$, \\ Zexian $\mathrm{Zhou}^{+}$and Lee D. Wilson* \\ Department of Chemistry, University of Saskatchewan, Saskatoon, SK, Canada
}

\section{OPEN ACCESS}

Edited by:

Tissa H. Illangasekare, Colorado School of Mines,

United States

Reviewed by:

Rohan Weerasooriya, National Institute of Fundamental

Studies (NIFS), Sri Lanka

Cleophas Achisa Mecha

Moi University, Kenya

${ }^{*}$ Correspondence: Lee D. Wilson

lee.wilson@usuask.ca

tThese authors have contributed equally to this work and share first

authorship

Specialty section: This article was submitted to Water and Human Health, a section of the journal

Frontiers in Water

Received: 11 July 2021

Accepted: 03 January 2022

Published: 15 February 2022

Citation:

Mohamed MH, Udoetok IA, Solgi M, Steiger BGK, Zhou Z and Wilson LD

(2022) Design of Sustainable

Biomaterial Composite Adsorbents for

Point-of-Use Removal of Lead lons

From Water. Front. Water 4:739492.

doi: 10.3389/frwa.2022.739492
The uncontrolled release of contaminants into aquatic environments has created the need for improved adsorbent materials for point-of-use (POU) treatment applications to address water security. The goal of this study was to prepare a low-cost sustainable adsorbent material with tailored $\mathrm{Pb}(\mathrm{II})$ adsorption properties in aqueous media. Several types of ternary composite adsorbents were prepared that contain chitosan, kaolinite, and a biomass additive (oat hulls or torrefied wheat straw), along with spectral characterization and thermal analysis of the adsorbents. The adsorption properties of the ternary composites with lead nitrate were studied at equilibrium using batch mode and dynamic conditions with a fixed bed column under variable experimental settings [flow rate, bed height, and $\mathrm{Pb}$ (II) concentration]. The adsorption capacity at equilibrium in synthetic or tap water was found to depend on the relative composition (wt.\%) of additive components in the composite. The optimal composite adsorbent for maximum $\mathrm{Pb}$ (II) removal had the following composition (wt.\%): chitosan (50\%) + kaolinite (10\%) + oat hulls (40\%). Using this adsorbent, the dynamic adsorption properties with lead nitrate were studied in a fixed bed column at pH 6.5 and $295 \mathrm{~K}$ to reveal optimized $\mathrm{Pb}(\mathrm{II})$ removal that concur with the results obtained from batch studies. The sustainability of the biocomposite adsorbent was demonstrated with the use of relatively low-cost and locally available materials, whilst achieving favorable $\mathrm{Pb}(\mathrm{II})$ adsorption properties. The facile preparation of the optimal biocomposite adsorbent herein is proposed for use as a disposable POU filter media technology for the removal of lead and other multivalent heavy metal cations, including organic contaminants such as cationic dyes and agrochemicals.

Keywords: chitosan, ternary composites, fixed-bed column, lead ions, adsorption, agricultural biomass

\section{INTRODUCTION}

The widespread occurrence of heavy metals in the environment has led to increasing concerns of such contaminants on human and ecosystem health. Among the various types of heavy metals, lead species have drawn widespread interest due to its utility in diverse industrial products such as batteries, paint pigments, agrochemicals, alloys, and infrastructure such as water distribution systems and pipelines. In North America, lead and iron piping systems are still in place in many urban centers for distribution of drinking water. The dissolution of lead species into drinking water 
supplies due to corrosion effects is known, where the Flint water crisis in Michigan (USA) brought international attention in 2014 (Santucci Jr and Scully, 2020). The improper use of corrosion inhibitors and water quality conditions in the distribution system led to exceedingly high levels of lead $(13,200 \mathrm{ppb})$ leaching into the drinking water supply for the city of Flint, where such values were ca. 900-fold higher than the 15-ppb limit set by the US EPA (Torrice, 2016). The elevated lead levels during the Flint crisis led to serious concerns for human health due to its neurotoxicity, behavioral and cognitive development effects, where ca. $10 \%$ of the children had significantly elevated blood levels in this region (Hanna-Attisha et al., 2016). The widespread occurrence of lead contamination was outlined due to leaching from the distribution systems in various Canadian cities (Cribb et al., 2019). In 2019, elevated lead levels were reported in two Saskatchewan cities, where the average value $(22 \mathrm{ppb})$ was above the prescribed maximum guideline (5 ppb) set forth by Health Canada (Wilson and Ackerman, 2019). Apart from other contaminants in drinking water, the occurrence of leadspecies such as $\mathrm{Pb}(\mathrm{II})$ has established the need to develop more accessible point-of-use (POU) methods to address such water security issues.

Among the various physical- and chemical-based techniques available: precipitation, biosorption, reverse osmosis, membrane filtration, electrocoagulation, and adsorption represent established methods for contaminant removal. As well, the infrastructure and operating costs for such techniques vary considerably, along with their relative efficiency of contaminant removal. In the case of adsorption-based methods, the infrastructure and operating costs are relatively low, whereas the efficiency of contaminant removal often depends on the nature of the adsorbent material. While there are various industrial adsorbents (e.g., activated carbon and zeolites) for metal-ion removal, there is ongoing interest in the development of sustainable biosorbents due to their renewable abundance and utilization in composite materials (Bailey et al., 1999; Shareef, 2009; Zhou and Haynes, 2010; Mudhoo et al., 2012; Pandey, 2020; Shakoor et al., 2020; Shabtai et al., 2021). The use of biopolymers such as chitosan and its modified forms for metal-ion adsorption are widely reported. In a recent review article, Shabtai et al. (2021) surveyed the use of additives such as clay among multi-component constituents for the preparation of composite materials. The incorporation of clay into composites may follow several strategies: adsorption, in-situ polymerization, cross-linking, and grafting. The adsorption approach is unique since it generally involves blending of the components and physical processing, whereas the other methods employ covalent modification and other chemical steps, according to the synthetic preparation. In an earlier study, Sabzevari et al. (2018) reported the synthesis of chitosan-graphene oxide (GO) composites using a facile method that revealed the ability to tailor the adsorption properties of such chitosan-GO composites toward cationic dyes in aqueous media. The tailoring of biocomposite adsorbents relates to the ability to alter their surface chemistry and textural properties. The variation of the additive composition within a multicomponent system represents a facile approach for meeting this goal, as reported elsewhere (Anisimov et al., 2020; Mohamed et al., 2020; Elanchezhiyana et al., 2021).

Herein, the overall goal of this study was to prepare low-cost and sustainable adsorbent materials with favorable adsorption properties toward $\mathrm{Pb}(\mathrm{II})$ species in aqueous media. To this end, several types of binary and ternary composite adsorbents were prepared and characterized, which contain chitosan, kaolinite, and biomass agro-waste (oat hulls or wheat straw) with variable composition. In turn, the adsorption properties of the ternary composites with lead nitrate was studied at equilibrium (batch mode) and under dynamic conditions with a fixed bed column at variable conditions. We demonstrate that such composite adsorbents can be prepared with tailored properties that are desirable for single-use applications for the controlled removal of $\mathrm{Pb}$ (II) from aqueous media. In turn, this study contributes to the science and technology of sustainable biocomposite adsorbents whilst employing a facile bottom-up synthetic method. We anticipate that such types of composite adsorbent materials are amenable as disposable POU water filters, especially for regions with limited access to advanced water treatment, to address the controlled removal of heavy metal cations such as lead and organic dyes (Mohamed et al., 2020).

\section{MATERIALS AND METHODS}

\section{Materials}

Chitosan was obtained from the POS Pilot Plant Corp. (Saskatoon, Canada). Kaolinite, $\mathrm{KBr}$ (spectroscopic grade), lead nitrate, sodium hydroxide, hydrochloric acid, and glacial acetic acid were obtained from Fisher Scientific Canada. All materials were of the highest chemical purity and were used as received without further purification. Oat hulls and wheat straw were sourced locally through the College of Engineering torrefaction plant (Prof. R. Evitts) at the University of Saskatchewan. Wheat straw was partially torrefied at $220^{\circ} \mathrm{C}$ for $10 \mathrm{~min}$ at the University of Saskatchewan (College of Engineering) torrefaction plant. The agro-waste biomass was ground using a coffee grinder and passed through a size 40 mesh sieve prior to use.

\section{Pellet Preparation}

The protocol for pellet preparation was adapted from another study (Mohamed et al., 2020). Chitosan pellets (CP) were prepared by mixing chitosan powder $(5 \mathrm{~g})$ with $15 \mathrm{~mL}$ of aqueous acetic acid $(0.2 \mathrm{M})$, followed by extruding the resulting paste through a syringe. The cylindrical extrudate was cut into $0.5 \mathrm{~cm}$ lengths, washed with $0.5 \mathrm{M}$ sodium hydroxide, followed by copious amounts of Millipore water to a neutral $\mathrm{pH}$, followed by air-drying. The composition of the CP-based materials were prepared by blending ternary mixtures that contain chitosan $(\mathrm{CP})$, kaolinite $(\mathrm{K})$, and biomass [oat hulls $(\mathrm{O})$ or torrefied straw (S)]. The pelletized adsorbents were prepared at different feed ratios on a weight (wt.\%) basis, as outlined in Table 1 for this study. 
TABLE 1 | Composition of the binary and ternary chitosan pellet (CP) biocomposites at variable weight content (\%).

\begin{tabular}{lcccc}
\hline $\begin{array}{l}\text { Adsorbent } \\
\text { sample ID }\end{array}$ & $\begin{array}{c}\text { Chitosan } \\
\text { (wt. \%) }\end{array}$ & $\begin{array}{c}\text { Kaolinite } \\
\text { (wt. } \%)\end{array}$ & $\begin{array}{c}\text { Oat hull } \\
\text { (wt. \%) }\end{array}$ & $\begin{array}{c}\text { Wheat straw } \\
\text { (wt. \%) }\end{array}$ \\
\hline CPK10 & 90 & 10 & 0 & 0 \\
CPK20 & 80 & 20 & 0 & 0 \\
CPKO20 & 70 & 10 & 20 & 0 \\
CPKO30 & 60 & 10 & 30 & 0 \\
CPKO40 & 50 & 10 & 40 & 0 \\
CPKS10 & 80 & 10 & 0 & 10 \\
CPKS20 & 70 & 10 & 0 & 20 \\
CPKS30 & 60 & 10 & 0 & 30 \\
CPKS40 & 50 & 10 & 0 & 40 \\
\hline
\end{tabular}

${ }^{a}$ Kaolinite $(K)$, oat hulls $(\mathrm{O})$ and torrefied wheat straw $(\mathrm{S})$ are defined for the adsorbent sample ID designation.

\section{Methods}

\section{Thermogravimetry Analysis}

Samples of the CP-based materials were prepared by grinding the pellets into a powder form using liquid nitrogen along with a mortar and pestle prior to the thermogravimetry analysis (TGA). TGA profiles were obtained using a TA Instruments Q50 Thermogravimetric analyzer that operated with a heating rate of $5^{\circ} \mathrm{C} \mathrm{min}^{-1}$ to a maximum temperature of $500^{\circ} \mathrm{C}$, where the sample was purged using nitrogen as the carrier gas. Thermal stability of the respective component materials was examined using first derivative (DTG) plots of weight with temperature $\left(\% /{ }^{\circ} \mathrm{C}\right)$ against temperature $\left({ }^{\circ} \mathrm{C}\right)$.

\section{Diffuse Reflectance Infrared Fourier Transform Spectroscopy}

The DRIFT spectra of the pellets were obtained using a BioRAD FTS-40 spectrophotometer. The pellets were crushed into powders with the aide of liquid nitrogen followed by mixing with pure spectroscopic grade $\mathrm{KBr}$ in a polymer/ $\mathrm{KBr}$ weight ratio of 1:10 using mortar and pestle. The spectra were obtained in reflectance mode at room temperature $\left(23^{\circ} \mathrm{C}\right)$ with a resolution of $4 \mathrm{~cm}^{-1}$ over the $400-4,000 \mathrm{~cm}^{-1}$ spectral range. Sixteen scans were recorded and corrected relative to a background spectrum of powdered $\mathrm{KBr}$.

\footnotetext{
${ }^{13} \mathrm{C}$ Solids NMR Spectroscopy

${ }^{13} \mathrm{C}$ solids NMR spectra of the powdered materials were acquired using a Bruker AVANCE III HD spectrometer equipped with a $4 \mathrm{~mm}$ DOTY CP-MAS (cross polarization with magic angle spinning) solids probe operating at $125.77 \mathrm{MHz}\left({ }^{1} \mathrm{H}\right.$ NMR frequency $=500.23 \mathrm{MHz})$, constant spinning speed $(10 \mathrm{kHz})$, with a fixed ${ }^{1} \mathrm{H}-90$ pulse $[3.5 \mu \mathrm{s}$, fixed contact time $(0.75 \mathrm{~ms})]$, and a ramp pulse on the ${ }^{1} \mathrm{H}$ channel. The spectra were recorded using 4,000 transients with a $2 \mathrm{~s}$ recycle delay, along with a $71 \mathrm{kHz}$ SPINAL-64 decoupling sequence during acquisition. Adamantane was used as the external standard $(\delta=38.48 \mathrm{ppm}$ for the low field adamantine signal) to reference the ${ }^{13} \mathrm{C}$ chemical shifts (ppm).
}

\section{Equilibrium Adsorption Study}

A stock solution of $100 \mathrm{ppm}$ (or $\mathrm{mg} / \mathrm{L}$ ) of lead was prepared using lead nitrate in $0.03 \mathrm{M}$ acetate buffer at $\mathrm{pH}$ 6.5. A series of aqueous solutions with variable lead concentration were prepared from a stock to cover a range $(80-100 \mathrm{ppm})$ of concentrations. A fixed weight of the CP-based adsorbent (ca. $60 \mathrm{mg}$ ) was added to $20 \mathrm{~mL}$ of the $\mathrm{PbNO}_{3}$ solution for variable stock concentration, followed by shaking on a horizontal shaker table for $24 \mathrm{~h}$ to achieve equilibrium (Udoetok et al., 2016).

\section{Lead Analysis}

The lead nitrate concentration before and after sorption was determined using a Varian SpectrAA 55 flame atomic absorption spectrophotometer. The lamp current was set to $5 \mathrm{~mA}$ while using an air-acetylene flame. The wavelength was $283.3 \mathrm{~nm}$ with a $0.5 \mathrm{~nm}$ slit width and optimum working range from 0.5 to $50 \mu \mathrm{g} / \mathrm{mL}$ similar to that reported elsewhere (Vafakish and Wilson, 2020). The calibration results for the $\mathrm{PbNO}_{3}$ analytical standards covered a linear range $\left(R^{2}=0.9915\right)$ between 5 and 100 ppm.

\section{Dynamic Adsorption Study}

A dynamic adsorption study for the continuous removal of lead was carried out in a glass column with a diameter of $20 \mathrm{~mm}$ and a bed height of $300 \mathrm{~mm}$. The column was packed with glass beads ( $2 \mathrm{~mm}$ diameter) at the bottom of the column to a height of $5 \mathrm{~cm}$ and $2 \mathrm{~cm}$ near the head of the column to conduct an upward flow of lead nitrate solution and to maintain the fixed bed within the column bed height. The fixed-bed column was equipped with a peristaltic pump to transfer the solution through the column from bottom to top, as previously described (Solgi et al., 2020). Three different external operating parameters for the dynamic adsorption process include the following: initial lead concentration $\left(\mathrm{C}_{0}\right)$, bed height $(\mathrm{Z})$, and flow rate $(\mathrm{Q})$. These parameters were studied to investigate the effect of different parameters that govern the adsorption of $\mathrm{Pb}$ (II) species on an optimized biocomposite adsorbent from Table 1. Before each experiment, a specific amount of CP-based pellets (CPKO40) were pre-soaked in Millipore water overnight to allow the adsorbent to reach a maximum level of equilibrium solvent swelling. During each experiment, a $2 \mathrm{~mL}$ sample of lead solution was collected at the outlet of the column to analyze the $\mathrm{Pb}$ (II) concentration at variable time intervals. The column adsorption experiment was continued until the concentration of lead in the effluent reached to the concentration value of lead in the influent solution $\left(C_{t} / C_{0}=1\right)$. The laboratory scale fixed-bed system is presented in Figure 1. The lead concentrations were estimated using atomic absorption spectrophotometry, as described above.

\section{RESULTS AND DISCUSSION}

A review of the literature reveals that studies describing the preparation of adsorbent materials for lead ion removal have emphasized adsorbent systems with a powder-like morphology (Beni and Esmaeili, 2020; Pandey, 2020; Shakoor et al., 2020; Boominathan and Sivaramakrishna, 2021; Shabtai et al., 2021). Despite the practical limitations of powdered adsorbents in 


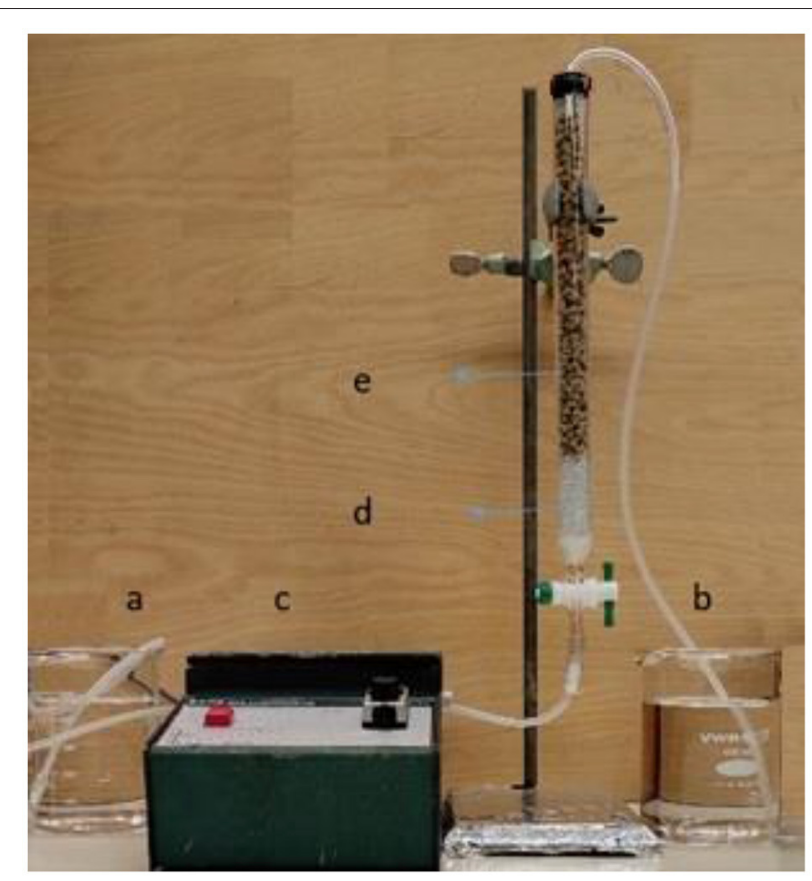

FIGURE 1 | The fixed-bed system for the adsorption of lead onto the CPKO40 ternary composite adsorbent system: (a) Influent, (b) effluent, (c) Peristaltic pump, (d) glass beads, and (e) CPKO40 ternary composite adsorbent.

column-based systems (Mohamed and Wilson, 2015; Patel, 2019), there are sparse reports that detail other types of adsorbent morphology for chitosan-based materials such as pelletized forms, as described herein (Syauqiah et al., 2015; Mohamed et al., 2017, 2020). This study describes a synthetic alternative to conventional covalent modification of biomaterials using a bottom-up preparation method for several types of binary and ternary adsorbent systems. The use of physically blended and pelletized extrudate forms of multicomponent adsorbents are proposed for the removal of $\mathrm{Pb}(\mathrm{II})$ under equilibrium and dynamic conditions. The biocomposites contain chitosan (CP), kaolinite $(\mathrm{K})$, and agro-waste biomass (oat hulls, $\mathrm{O}$; or wheat straw, S), where the sample ID in Table 1 denotes the relative composition of the additive components. In the accompanying sections below, the CP materials were structurally characterized by several complementary methods: spectroscopic (IR and ${ }^{13} \mathrm{C}$ NMR) and thermal gravimetry analysis. A study of the adsorption properties of the $\mathrm{CP}$ materials was carried out at equilibrium conditions to evaluate the maximum adsorption capacity $\left(\mathrm{Q}_{\mathrm{m}}\right)$ for $\mathrm{Pb}(\mathrm{II})$ species in aqueous lead nitrate solutions at $\mathrm{pH} 5$ and 6.5 with the use of purified laboratory and tap water. Then, an optimal CP material formulation was selected for further study under dynamic conditions for a fixed-bed column study at $\mathrm{pH}$ 6.5 , where various parameters such as column flow rate, bed height, and lead concentration are evaluated to characterize the column efficiency for practical applications.

\section{Thermogravimetry Analysis}

Thermogravimetry analysis (TGA) of weight loss profiles vs. temperature provide insight on the thermal stability and compositional information of components in such composites (Sabzevari et al., 2018). The thermal stability profiles of CP, single component additives and the various CP-based composites (binary and ternary) are shown in Figures 2A-D. The profiles are presented as derivative (DTG) profiles, as plots of derivative weight $\left(\% /{ }^{\circ} \mathrm{C}\right)$ vs. temperature $\left({ }^{\circ} \mathrm{C}\right)$. The DTG profiles of the biomaterials and kaolinite (Figure 2A) reveal that the agro-waste biomass $(\mathrm{O}, \mathrm{S})$ have a slighter broader range of thermal stability vs. the chitosan pellet (CP) material. The former may relate to the presence of (hemi)cellulose and lignins, which impart greater thermal stability to the agro-waste biomass over chitosan alone (Alabi et al., 2020; Dehabadi et al., 2020). By contrast, kaolinite $(\mathrm{K})$ remains stabile over this temperature range, in line with a reported decomposition temperature of $521^{\circ} \mathrm{C}$ (Cheng et al., 2010). Binary composites $(\mathrm{CP}+\mathrm{K})$ show comparable TGA profiles relative to $\mathrm{CP}$ in Figure $\mathbf{2 B}$, where evidence of the presence of micropore domains and/or ionic adsorption sites is revealed by the extended thermal stability profile of water desorption between 100 and $200^{\circ} \mathrm{C}$ for these binary composites. By comparison, ternary composites show incremental mass loss contributions in the $250-375^{\circ} \mathrm{C}$ region that concur with the loss of biomass content, where the appearance of more fine structure may indicate the role of adhesive (electrostatic) interactions between $\mathrm{CP}$ or $\mathrm{K}$ with the biomass agro-waste components [(hemi)cellulose and lignins], as evidenced in Figures 2C,D.

\section{IR Spectroscopy}

Infrared (IR) spectroscopy provides general structural information related to the presence of functional groups in composite materials and the presence of additive components, according to the presence of resolvable spectral signatures, as seen in Figure 3 and the Supporting Materials (cf. Supplementary Figures S1, S2). The IR spectra for CP and the biomass $(\mathrm{S}, \mathrm{O})$ share similar features that are characteristic of typical of polysaccharide materials: $-\mathrm{OH} /-\mathrm{NH}$ groups $(3,000-$ $\left.3,700 \mathrm{~cm}^{-1}\right)$; $-\mathrm{CH}$ groups $\left(\sim 2,900 \mathrm{~cm}^{-1}\right)$; carbonyl or amide (1,650-1,750 $\left.\mathrm{cm}^{-1}\right)$; C-C (1,500-1,600 $\left.\mathrm{cm}^{-1}\right)$; C-H bending (1,300-1,450 $\left.\mathrm{cm}^{-1}\right)$; C-O/C-O-C (1,000-1,200 $\left.\mathrm{cm}^{-1}\right)$; and glycosidic $\left(1,075 \mathrm{~cm}^{-1}\right)$ bonds (Zawadzki and Kaczmarek, 2010; Alabi et al., 2020; Dehabadi et al., 2020). Kaolinite differs due to its aluminosilicate structure, as follows: -OH groups (3,600-3,700 cm $\left.\mathrm{cm}^{-1}\right)$, Si-O $\left(1,000-1,150 \mathrm{~cm}^{-1}\right)$, Al-OH (900-950 $\left.\mathrm{cm}^{-1}\right)$, Si-O-Al (750-800 $\left.\mathrm{cm}^{-1}\right)$, and Si-O/Si-O-Al (400-550 $\left.\mathrm{cm}^{-1}\right)$. Signals for the lignins are mostly overlapping with the IR bands for hemicellulose. However, a characteristic signature near $1,508 \mathrm{~cm}^{-1}$ can be inferred (within oat hull and wheat straw) as skeletal aromatic vibrations (Horikawa et al., 2019), which are absent for chitosan (CP) and kaolinite (K) in Figure 3. The CP composites (CPKS40, CPKO40, and CPK10) reveal IR signatures that are present in the single component materials, where evidence of spectral broadening relates to electrostatic interactions between the respective components due to the presence of polar donor-acceptor groups. In summary, the IR results in Figure 3 and Supplementary Figure S1 provide support for the presence of $\mathrm{CP}, \mathrm{K}$, and agro-waste biomass in the composites, which concur with their variable mass composition 

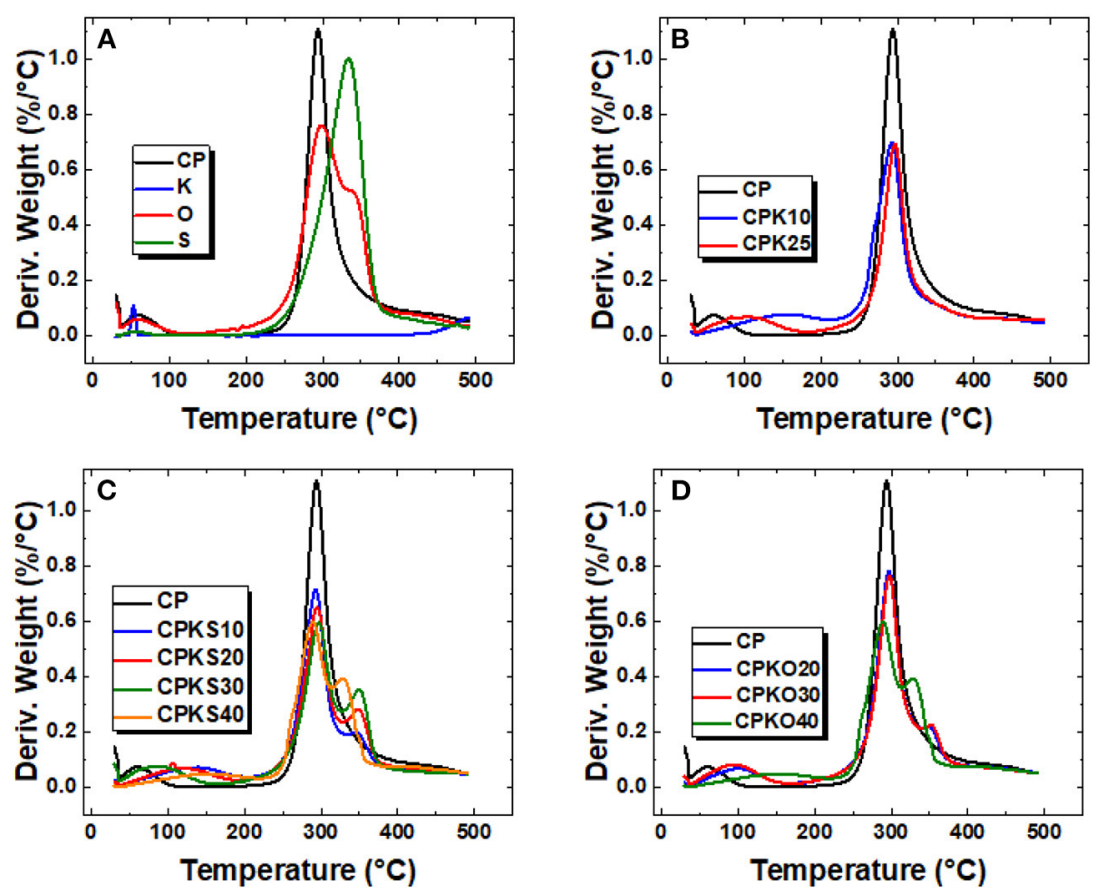

FIGURE 2 | (A-D) Derivative plots (DTG) profiles for various materials: (A) Single component materials used for the composite pellets, (B) CPK-based, (C) CPKS-based, and (D) CPKO-based pellets at various weight (\%) composition.

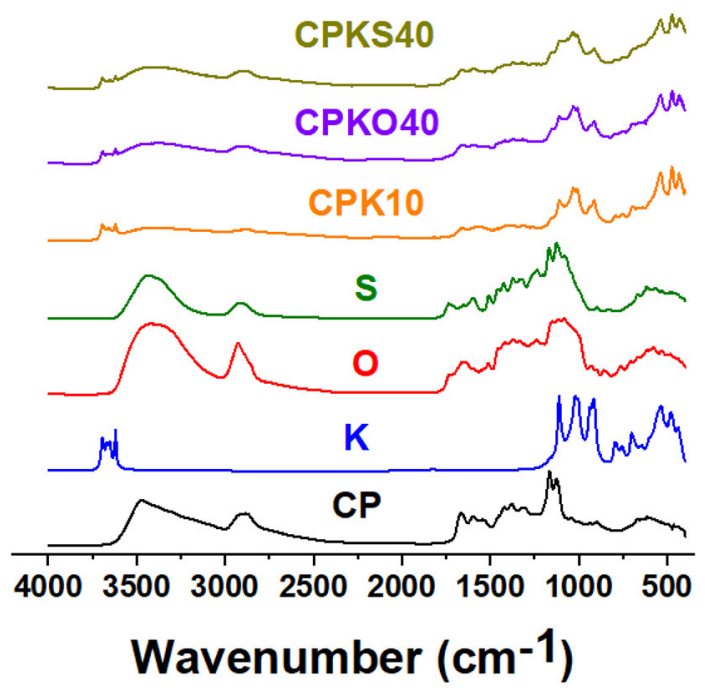

FIGURE 3 | Normalized FTIR spectra in reflectance mode for various materials in their powdered form: CP, K, O, S, CPK10, CPKO40, and CPKS40 materials.

(cf. Table 1) and the thermal stability of single components and mixed systems for the case of composites (Sabzevari et al., 2018).

\section{${ }^{13} \mathrm{C}$ Solids NMR Spectroscopy}

${ }^{13} \mathrm{C}$ solids NMR spectroscopy provides valuable structural information related to the carbon skeletal framework of organic

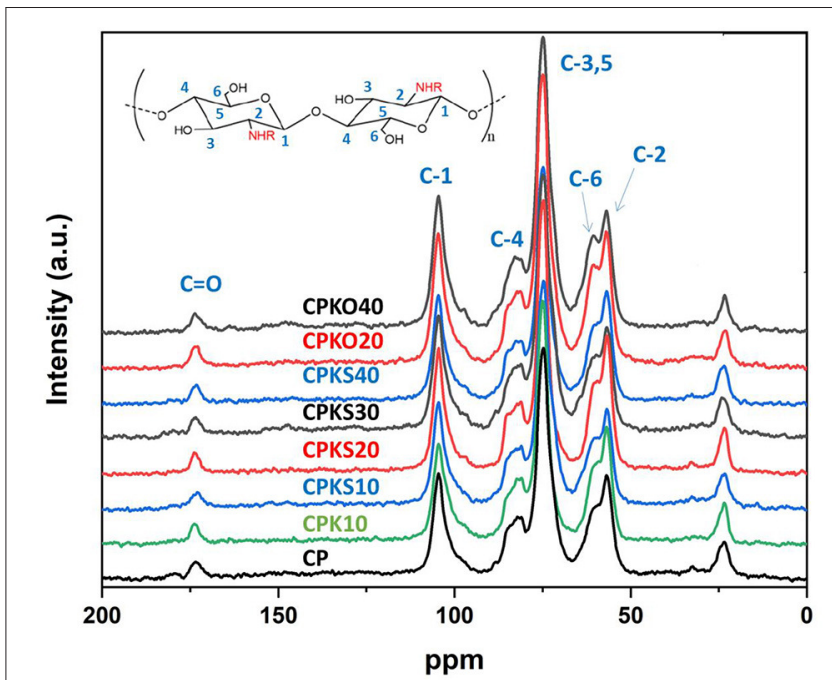

FIGURE $4 \mid{ }^{13} \mathrm{C}$ CP-MAS solids NMR spectra for CP and its composites with kaolinite and agro-waste biomass components $(\mathrm{O}, \mathrm{S})$, as described in Table 1. NHR refers to amine or amide $\left(\mathrm{R}=\mathrm{H}\right.$ or $\left.\mathrm{R}=\mathrm{COCH}_{3}\right)$, in accordance with the level of deacetylation of chitosan (see inset). The carbon- numbering scheme is denoted in the inset and labeled in the uppermost spectrum.

materials and multi-component systems such as composites, especially when the spectral signatures are well-resolved (Anisimov et al., 2020). Figure 4 illustrates the ${ }^{13} \mathrm{C}$ solids NMR spectra for $\mathrm{CP}$ and its binary and ternary composites. Similar 

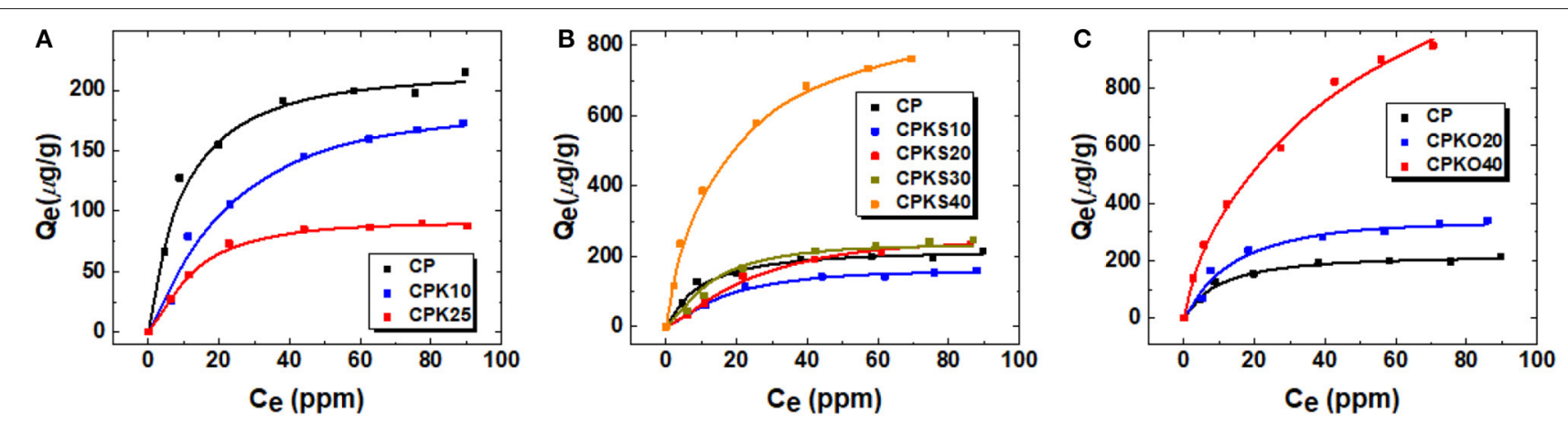

FIGURE 5 | (A-C) Sorption isotherms for the uptake of $\mathrm{Pb}^{2+}$ by $\mathrm{CP}$ and various CP-based composite adsorbents at ambient temperature and pH 6.5: (A) kaolinite, (B) torrefied wheat straw, and (C) oat hulls. The solid lines represent the best-fit results according to the Sips isotherm model.

spectral features are noted for the polysaccharide region for chitosan and the agro-waste biomass components (oat hulls, wheat straw). The glucopyranose units (see inset) of chitosan overlap with the polysaccharide fraction of the biomass due to the dominant contribution of the pyranose units of cellulose and hemicellulose for these lignocellulosic materials. The absence of apparent arene signatures can be related to the relatively low lignin content of the biomass, except for composites that contain higher fractions of agro-waste biomass such as CPKO40 and the composite containing torrefied wheat straw (CPKS10 to S40) in Figure 4. This is in contrast to the dominant fraction of (hemi)celluloses of agro-waste biomass. The relatively low lignin content is further supported by the results in Figure 3 that concur with the absence of any notable $\mathrm{C}-\mathrm{H}$ vibrational signatures $\sim 3,100 \mathrm{~cm}^{-1}$. Another contributing factor that may affect the ability to detect low content (below 10\%) of lignins relates to the reduced motional dynamics of lignins for such arene species. This is in contrast to the polysaccharide fraction which have greater motional dynamics in the solid state, according to ${ }^{13} \mathrm{C}$ relaxation times for lignins $\left(\mathrm{T}_{1}=5-8 \mathrm{~s}\right)$, which exceed the $T_{1}$ values obtained for polysaccharides (Kang et al., 2019).

\section{Equilibrium Adsorption}

The adsorption properties of $\mathrm{CP}$ and its other pelletized composite materials (binary and ternary) were evaluated in aqueous media that contain lead nitrate, where $\mathrm{Pb}^{2+}$ is inferred to have favorable affinity to the CP-based adsorbents due to the Lewis base character of such lignocellulosic-based composites and the Lewis acid nature of $\mathrm{Pb}^{2+}$ (de Oliveira et al., 2017; Gao et al., 2018). Due to the water insolubility of the pelletized composite materials, the uptake of $\mathrm{Pb}^{2+}$ can be determined based on the ability to carry out phase separation of the adsorbent from the aqueous solution after the adsorption process, according to Equation (1). Other studies that employ Equation (1) for the case of dye-based probes is described elsewhere for other types of multi-component biocomposites and their adsorption properties (Sabzevari et al., 2018; Anisimov et al., 2020; Dehabadi et al., 2020). Herein, the $\mathrm{Pb}(\mathrm{II})$ uptake of the single component additives (chitosan, kaolinite, and oat hulls) in their powdered form were evaluated at $\mathrm{pH} 5$ and 6.5 in synthetic water in acetate buffer $(30 \mathrm{mM})$, along with tap water at $\mathrm{pH} 5$ (cf. Supplementary Figure S3). The general trend in $\mathrm{Pb}$ (II) uptake for the single component additives in their powdered form are listed in descending order: oat hulls $(\sim 18 \mathrm{mg} / \mathrm{g})>$ chitosan $(\sim 10$ $\mathrm{mg} / \mathrm{g})>$ kaolinite $(\sim 4.5 \mathrm{mg} / \mathrm{g})$. The $Q_{\mathrm{e}}$ values (cf. Equation 1 ) in parentheses correspond to initial $\mathrm{Pb}$ (II) levels at $60 \mathrm{mg} / \mathrm{L}$. The results indicate that kaolinite has limited uptake of $\mathrm{Pb}(\mathrm{II})$ despite its known cation exchange properties, whereas the biomaterials display greater uptake of $\mathrm{Pb}$ (II) due to the polar functional groups (e.g., - $\mathrm{OH},-\mathrm{COOH}$ ) of polysaccharides and lignins, along with their known chelation properties (Beni and Esmaeili, 2020; Sajjadi et al., 2021) with metal-ion species.

$$
Q_{e}=\frac{\left(C_{o}-C_{e}\right) \times V}{m}
$$

$Q_{e}$ is the level of adsorbed lead $(\mu \mathrm{g} / \mathrm{g}$ ) by the CP-based adsorbent at equilibrium, $V(\mathrm{~L})$ is the volume of lead solution, $\mathrm{m}$ is the mass of the pellets $(\mathrm{g}), C_{o}(\mu \mathrm{g} / \mathrm{L})$, and $C_{e}(\mu \mathrm{g} / \mathrm{L})$ are the initial and final (residual amount in solution at equilibrium) $\mathrm{Pb}$ (II) concentration, respectively. $C_{o}$ and $C_{e}$ also refer to the adsorbate concentration before and after the adsorption process in Equation (1).

A series of adsorption isotherms ( $c f$. Figures 5A-C) were obtained at $\mathrm{pH} 6.5$ in aqueous media for the various CPbased adsorbents (cf. Table 1) to evaluate the effect of additive components, according to the $\mathrm{Pb}$ (II) adsorption properties in aqueous media. The results are expressed by plotting $Q_{e}$ vs. $C_{e}$ over a range of $\mathrm{Pb}(\mathrm{II})$ adsorbate concentration (ppm). Turning to Figure 5A, the uptake profile adopts behavior typical of Langmuir-type adsorption (Sabzevari et al., 2018), where the uptake of $\mathrm{Pb}(\mathrm{II})$ is greater for $\mathrm{CP}$ relative to its binary composites with kaolinite (CPK10 and CPK25). While kaolinite has favorable affinity toward metal-ion species due to its known cation exchange capacity (CEC) (Ma and Eggleton, 1999). The formation of a composite with $\mathrm{CP}$ appears to attenuate the adsorption properties for the binary CPK-based composites. This may be due to reduced access of the Lewis base sites of the biomass and/or the cation exchange sites of kaolinite, in agreement with the results in Supplementary Figure S3 described above. The observed uptake of $\mathrm{Pb}(\mathrm{II})$ by $\mathrm{CP}$ relates 
TABLE 2 | Adsorption parameters for CP-based adsorbents with $\mathrm{Pb}$ (II) in aqueous media at pH 6.5 and $295 \mathrm{~K}$, according to the Sips isotherm model (cf. Equation 2).

\begin{tabular}{lccc}
\hline Sorbent material & $\mathbf{Q}_{\mathbf{m}}(\boldsymbol{\mu} \mathbf{g} / \mathbf{g})$ & $\mathbf{K}_{\mathbf{s}}(\mathbf{L} / \mathbf{g})$ & $\boldsymbol{n}_{\mathbf{s}}$ \\
\hline CP & $218 \pm 22$ & 126 & 1.22 \\
CPK10 & $190 \pm 19$ & 55.5 & 1.37 \\
CPK25 & $91.5 \pm 9.2$ & 94.6 & 1.72 \\
CPKS10 & $163 \pm 16$ & 72.7 & 1.68 \\
CPKS20 & $259 \pm 26$ & 49.6 & 1.59 \\
CPKS30 & $309 \pm 31$ & 80.9 & 1.35 \\
CPKS40 & $994 \pm 99$ & 66.8 & 0.940 \\
CPKO20 & $345 \pm 35$ & 97.3 & 1.35 \\
CPKO40 & $1,910 \pm 190$ & 14.8 & 0.777 \\
\hline
\end{tabular}

to the metal-ion chelation properties of chitosan (Gao et al., 2018; Wilson and Tewari, 2018) due to its abundant amine and hydroxyl groups (see inset in Figure 4 above). In Figure 5B, the uptake profile likewise follows Langmuir-type behavior for $\mathrm{CP}$ and its ternary composites that contain wheat straw (S) (Dehabadi et al., 2020; Mohamed et al., 2020). Based on the various isotherms, the composites that contain $10-30 \% \mathrm{~S}$ show comparable uptake properties to CP. By contrast, CPKS40 has notably pronounced uptake of $\mathrm{Pb}$ (II) relative to the other $\mathrm{CP}$ based materials. A parallel trend is observed in Figure 5C for the oat hull biomass composites, where CPKO40 has notably higher uptake with $\mathrm{Pb}(\mathrm{II})$ relative to $\mathrm{CP}$ and $\mathrm{CPKS} 20$. It is noteworthy that the overall uptake of CPKO40 exceeds that of CPKS40, where this may be attributed to the role of surface polar groups [e.g., lignins and (hemi)cellulose] for each type of biomass. It should be noted that the wheat straw was torrefied at $200^{\circ} \mathrm{C}$, whereas the oat hulls were used in their pristine form. The torrefaction of biomass typically results in the loss of surface functional groups according to the extent of torrefaction. The latter concurs with the thermal decomposition profile noted in the TGA results (cf. Figure 2A) for biomass $(\mathrm{O}, \mathrm{S})$ and concurs with the greater hydrophobicity of torrefied biomass due to the use of reducing conditions during torrefaction. The incorporation of torrefied straw into CPbased adsorbents may result in materials with greater lipophile character due to the loss of polar functional groups from the biomass, as shown by the affinity of apolar anionic organic dyes versus a lower affinity observed for hydrophilic inorganic anions (Mohamed et al., 2020).

To gain insight on the adsorption isotherm parameters, the Sips isotherm model (Sips, 1948; Guo et al., 2021) was employed since it accounts for features of the Langmuir and Freundlich models, as depicted by Equation (2).

$$
Q_{e}=\frac{Q_{m}\left(K_{s} C_{e}\right)^{n_{s}}}{1+\left(K_{s} C_{e}\right)^{n_{s}}}
$$

The Sips isotherm model has three adjustable parameters, where $K_{s}(\mathrm{~L} / \mathrm{g})$ is the Sips equilibrium constant, $\mathrm{Q}_{\mathrm{m}}(\mu \mathrm{g} / \mathrm{g})$ is the monolayer adsorption capacity, and $n_{s}$ is an exponential term referred to as the heterogeneity factor. The Sips isotherm provided the best-fit to the isotherm results and yielded estimates of the adsorption parameters (cf. Table 2). The monolayer adsorption capacity $\left(\mathrm{Q}_{\mathrm{m}}\right)$ provides a selection criteria for screening the relative uptake properties of adsorbents, as described in recent reviews (Beni and Esmaeili, 2020; Shabtai et al., 2021). As well, $Q_{m}$ provides a basis for comparison with the $\mathrm{Q}_{\mathrm{e}}$ term derived from the best-fit results for the dynamic column studies (vide infra). The exponential term $\left(\mathrm{n}_{\mathrm{s}}\right)$ in Equation (2) provides an indication of the homogeneity $\left(n_{s}=1\right)$ or the heterogeneity $\left(n_{s} \neq 1\right)$ of the adsorption sites on the adsorbent surface (Guo et al., 2021).

An evaluation of the $\mathrm{Q}_{\mathrm{m}}$ values in Table 2 for $\mathrm{CP}$ and its composites reveal that $\mathrm{CPKO} 40$ has the highest adsorption capacity among the two types of biomass composites. The uptake of $\mathrm{Pb}(\mathrm{II})$ correlates with greater biomass content, where the role of biomass was inferred to provide greater accessibility to the active sites of the CP material in an independent study (Mohamed et al., 2020). The exponential term $\left(\mathrm{n}_{\mathrm{s}}\right)$ deviates from unity, which suggests that the adsorption sites are not homogeneous on the biocomposite surface. The variable adsorptive contributions of the polar groups concur with the polysaccharide $(-\mathrm{OH},-\mathrm{NHR})$ and lignocellulosic (phenolic, $\mathrm{COOH})$ fractions of the ternary composites. The presence of biomass $(\mathrm{S}$ and $\mathrm{O})+$ chitosan + kaolinite appear to function synergistically when the biomass content reaches $40 \mathrm{wt} . \%$, where the contribution of $\mathrm{O}$ exceeds $\mathrm{S}$ by two-fold, based on the $\mathrm{Q}_{\mathrm{m}}$ values in Table 2. The role of O-heteroatom adsorption sites is supported by the respective $\mathrm{Pb}(\mathrm{II})$ uptake results for kaolinite, chitosan, and oat hull fractions (cf. Supplementary Figure S3). In brief, the relative uptake capacity for these single component materials with $\mathrm{Pb}$ (II) are listed in descending order: oat hulls $>$ chitosan $>$ kaolinite. This trend parallels with the relative abundance of polar $\mathrm{O}$-atom functional groups for these materials and also indicates that oat hulls serve as the active site for $\mathrm{Pb}$ (II) in composites containing such agro-waste biomass. Based on the results in Figure 5 and Table 2, the CPKO40 composite displays significant improvement in uptake over $\mathrm{CP}$, according to its 5fold greater $\mathrm{Pb}(\mathrm{II})$ uptake. Chitosan shows variable electrostatic potential with $\mathrm{pH}$ near its $\mathrm{pK}_{\mathrm{a}}$, as reported by Franca et al. (2008), where the incorporation of oat hulls along with kaolinite into chitosan pellets (CP) highlights a significant improvement in the adsorption properties, according to the key role of the oat hulls.

According to Table 2, the deviation of the heterogeneity factor $\left(n_{s}\right)$ from unity $\left(n_{s} \neq 1\right)$ indicates the role of heterogeneous multi-adsorption sites (cf. illustration in Figure 6, vide supra) for the uptake of $\mathrm{Pb}(\mathrm{II})$. This is corroborated by the NMR spectral results ( $c f$. Figure 4), which reveal the increasing presence of lignins (ca. 125-160 ppm region) for composites that contain greater content of biomass (oat hulls and torrefied wheat straw). In addition, FT-IR spectroscopy (cf. Figure 3) also reveal the complexity of the materials and overlapping signals in the regions $\left(1,600-1,000 \mathrm{~cm}^{-1}\right)$ that provide spectral support of lignins within the ternary composites. Based on the trends in Figure 5 and the $\mathrm{Q}_{\mathrm{m}}$ values in Table 2, the agro-waste biomass was inferred to play a key role for the adsorption of $\mathrm{Pb}(\mathrm{II})$. The composition of such agro-waste is mainly (hemi)cellulose and lignins, where the predominant binding sites can be related to the hydroxyl $(-\mathrm{OH})$ groups of the polysaccharide or the phenolic and 


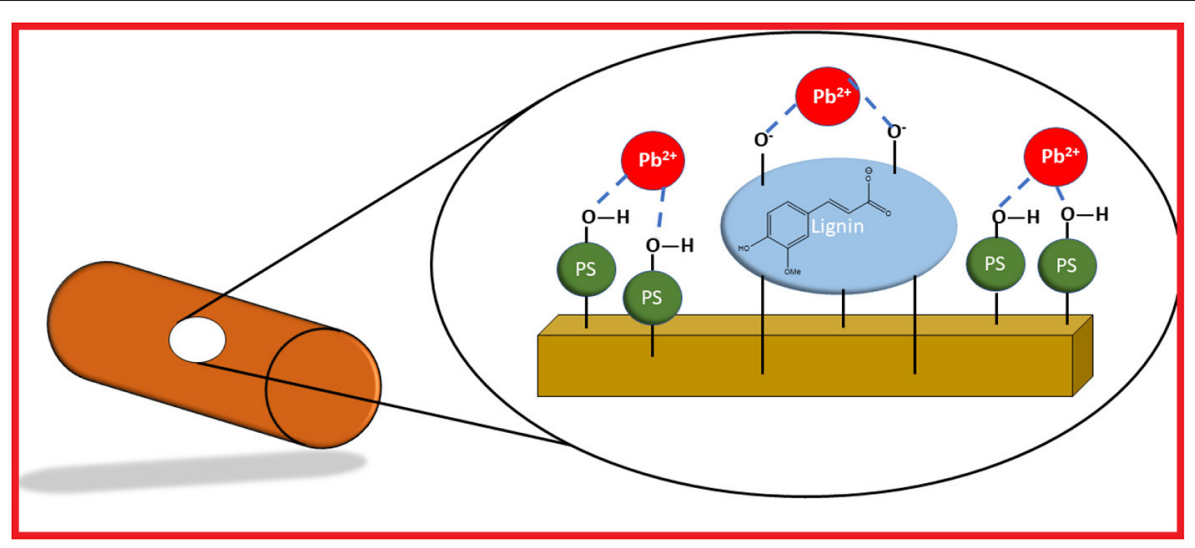

FIGURE 6 | Illustrative view of multi-adsorption sites for the hydroxyl groups of the polysaccharide (PS-OH) fraction of the ternary composite, whereas the lignin site is depicted by an ionized ferulic acid as a model lignin constituent to illustrate an active ion-exchange site for Pb(II). The brown cylinder represents the pelletized morphology of the biocomposite adsorbent, where the role of hydration was omitted for the sake of clarity for this process.

-COOH groups of lignins in the lignocellulosic biomass fraction (oat hulls and wheat straw).

The greater uptake of $\mathrm{Pb}$ (II) from $\mathrm{pH} 5$ to 6.5 in laboratory and tap water, along with the range in $\mathrm{pK}_{\mathrm{a}}$ values for lignins $\left(\mathrm{pK}_{\mathrm{a}}\right.$ phenolics' $\left.\sim 6.2-11.3\right)$. This includes the less acidic polysaccharide fraction of the biomass such as hemi (cellulose), which possess higher $\mathrm{pK}_{\mathrm{a}}$ values between 11 and 12. The greater acidity of the lignins concurs with their lower $\mathrm{pK}_{\mathrm{a}}$ values, which supports their primary role as ion-exchange sites for the adsorption of $\mathrm{Pb}(\mathrm{II})$. The greater uptake of $\mathrm{Pb}(\mathrm{II})$ between $\mathrm{pH}$ 5 and 6.5 (cf. Supplementary Figure S3) parallels the greater ionization tendency of the phenolic hydroxyl groups of the lignins, in agreement with a report by Ragnar et al. (2000). By contrast, the $-\mathrm{OH}$ groups of the polysaccharide (PS-OH) do not undergo ionization over this range since the average $\mathrm{pK}_{\mathrm{a}} \sim 10-12$ (Sajjadi et al., 2021) for the (hemi)cellulose fraction lies well above the $\mathrm{pH}$ conditions of the solution at $\mathrm{pH} 6.5\left(\mathrm{pH}<<\mathrm{pK}_{\mathrm{a}}\right.$; PS-OH groups). An illustration of the primary role of ionized lignin sites and the non-ionized polysaccharide sites are shown schematically in Figure 6.

Given that the isotherm results reported in Figure 5 and Table 2 were obtained using laboratory prepared water samples, there is a need to understand the role of $\mathrm{Pb}(\mathrm{II})$ adsorption in more complex matrices that resemble environmental samples. To gain insight on the role of competitor ion effects on the uptake of $\mathrm{Pb}(\mathrm{II})$, the adsorption properties of $\mathrm{CPKO} 40$ was evaluated in the presence of a various single component dication species; $\mathrm{Fe}(\mathrm{II}), \mathrm{Ca}(\mathrm{II}), \mathrm{Mg}(\mathrm{II})$, and $\mathrm{Cu}(\mathrm{II})$, respectively. In Supplementary Figure S4, the equilibrium $\mathrm{Pb}$ (II) uptake results are shown for CPKO40 in the presence of single component metal cations at pH 5 and 6.5 in $30 \mathrm{mM}$ acetate buffer, along with tap water samples at $\mathrm{pH}$ 5. As well, the uptake of $\mathrm{Pb}$ (II) was compared in an equimolar metal cation mixture to approximate the conditions of environmental samples. Based on the uptake results at $\mathrm{pH} 5$ in tap and synthetic water, the presence of single component cations $\left(0.05 \mathrm{mM}, 3.28 \mathrm{mg} / \mathrm{L}\right.$ for $\mathrm{Cu}^{2+}, 1.22 \mathrm{mg} / \mathrm{L}$ for $\mathrm{Mg}^{2+}, 2.79 \mathrm{mg} / \mathrm{L}$ for $\mathrm{Fe}^{2+}, 2.00 \mathrm{mg} / \mathrm{L}$ for $\mathrm{Ca}^{2+}, 10 \mathrm{mg} / \mathrm{L}$ for $\mathrm{Pb}^{2+}$ ) or their equimolar mixtures show negligible effects on the uptake of $\mathrm{Pb}(\mathrm{II})$. By comparison, the results for synthetic water at $\mathrm{pH} 6.5$ show systematically greater $\mathrm{Pb}(\mathrm{II})$ uptake, along with negligible effects due to such competitor cations. Sajjadi et al. (2021) have also reported on the relative affinity of $\mathrm{Pb}^{2+}$ by lignins over other competitor cations in descending order, as follows: $\mathrm{Pb}^{2+}>\mathrm{Cu}^{2+}>\mathrm{Zn}^{2+}>\mathrm{Cd}^{2+}>\mathrm{Ca}^{2+}$. This trend is also borne out by the negative zeta-potential of oat hulls reported elsewhere (cf. Table 2 in de Oliveira et al., 2017), where lignins serve as the primary adsorption site for $\mathrm{Pb}(\mathrm{II})$, as illustrated in Figure 6.

In contrast with oat hulls, the lower uptake of $\mathrm{Pb}$ (II) for chitosan at $\mathrm{pH} 6.5$ is understood due to its charge repulsions with $\mathrm{Pb}(\mathrm{II})$ since chitosan adopts a positive charge at $\mathrm{pH}$ values below its $\mathrm{pK}_{\mathrm{a}}\left(\mathrm{pK}_{\mathrm{a}}\right.$, chitosan $\left.\approx 6.7\right)$. As well, $\mathrm{Pb}(\mathrm{II})$ exists as a doubly charged cation species up to $\mathrm{pH} 6.5$ (Powell et al., 2009; Huang, 2016; Overah and Ifeanyi, 2017). This further illustrates the key contribution of bentonite (Au and Leong, 2016) and oat hulls (de Oliveira et al., 2017) to the negative surface charge of the ternary composite, according to their negative zeta-potential contributions at $\mathrm{pH}$ 6.5. The overall negative surface charge for CPKO40 is consistent with an independent study reported by $\mathrm{Li}$ and Bai (2005), where the point-of-zero (PZC) charge for chitosan-cellulose hydrogel composites was estimated at $\mathrm{pH}=$ 6.7. The contribution of bentonite and lignocellulose components in CPKO40 is estimated to have an even lower PZC value. In addition to the equilibrium study outlined above, an evaluation of the adsorption properties of $\mathrm{CPKO} 40$ with $\mathrm{Pb}$ (II) under dynamic conditions is shown to provide further insight on the utility of such CP adsorbents for practical POU applications, as outlined in the next section (cf. Dynamic Adsorption Results) and following.

\section{Dynamic Adsorption Results Analysis of Fixed-Bed Column Data}

Adsorption processes in a continuous system have the potential to treat large volumes of contaminated water with high efficiency. Also, the fixed-bed column experiments provide useful 

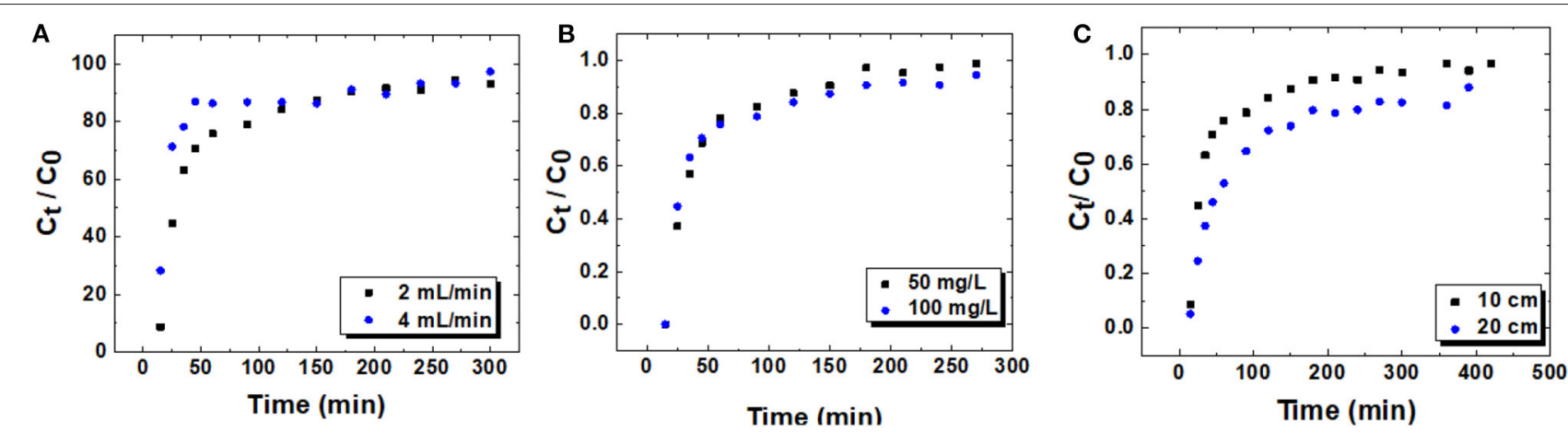

FIGURE 7 | (A-C) Breakthrough curves for the adsorption of lead ions onto CPKO40 at; (A) different flow rates. $Z=10 \mathrm{~cm}, \mathrm{C}_{0}=100 \mathrm{mg} / \mathrm{L}$, and pH = 6.5, (B) different initial $\mathrm{Pb}(\mathrm{II})$ concentration. $Z=10 \mathrm{~cm}, \mathrm{pH}=6.5$, and flow rate $=2 \mathrm{~mL} / \mathrm{min}$, and $\mathbf{( C )}$ different bed heights. $C_{0}=100 \mathrm{mg} / \mathrm{L}, \mathrm{pH}=6.5$, and flow rate $=2$ $\mathrm{mL} / \mathrm{min}$.

information in terms of scale-up for field-based applications (de Franco et al., 2017). Based on the equilibrium adsorption results in Table 2, it was established that the CP-based composite (CPKO40) containing 40\% oat hulls was the optimal adsorbent material. Consideration of the relative permeability and morphology of the CP materials reveals their potential utility for such fixed-bed column studies (Solgi et al., 2020). The greater adsorption capacity for CPKO40 listed in Table $2\left(\mathrm{Q}_{\mathrm{m}}=\right.$ $1,910 \mu \mathrm{g} / \mathrm{g}$ ) provided the basis for selection of this CP material for the fixed-bed column study. The parallel trend of the batch results in Table 2 with the dynamic adsorption properties is further described in the sections below.

To characterize the adsorbent properties in a continuous adsorption process, an analysis of the breakthrough curve profiles is a key requirement. The breakthrough curve is a plot of the ratio of adsorbate concentration in the effluent $\left(C_{t}\right)$ relative to the concentration of adsorbate in the influent $\left(\mathrm{C}_{0}\right)$ against time. Equations (3-9) were obtained by mass-balance for any ion at any given time are considered useful for a complete interpretation of the breakthrough curves (Basu et al., 2019; Solgi et al., 2020).

$$
\begin{aligned}
m_{a d, t} & =m_{\text {in,t }}-m_{\text {out }, t} \\
m_{\text {out }} & =C_{0} Q \int_{0}^{t}\left(\frac{C}{C_{0}}\right) d t \\
q_{m} & =\frac{m_{a d, t}}{M}=\frac{C_{0} Q \int_{0}^{t}\left(1-\frac{C}{C_{0}}\right) d t}{M} \\
R(\%) & =\frac{m_{a d, t}}{m_{\text {in,t }}} 100 \\
m_{\text {in,t }} & =1000 \cdot Q \cdot C_{0} \cdot t \\
V_{s} & =Q \cdot t_{s} \\
V_{b} & =Q \cdot t_{b}
\end{aligned}
$$

Based on the above relations, the term $\mathrm{m}_{\mathrm{in}, \mathrm{t}}(\mathrm{mg})$ is the level of $\mathrm{Pb}$ (II) ions entering into the column at any specific time $\mathrm{t}, \mathrm{m}_{\text {out, }} \mathrm{t}$ (mg) denotes as the amount of non-adsorbed lead ions in the effluent at any time $t, \mathrm{C}_{0}$ is the lead concentration in the influent $(\mathrm{mg} / \mathrm{L})$, and $\mathrm{C}_{\mathrm{t}}$ is the $\mathrm{Pb}(\mathrm{II})$ concentration at any given time $\mathrm{t}$ in the effluent. $\mathrm{M}(\mathrm{g})$ is the amount of adsorbent packed in the
TABLE 3 | Parameters obtained from breakthrough curves at variable operating conditions for the adsorption of $\mathrm{Pb}$ (II) ions onto $\mathrm{CPKO} 40$ at pH 6.5 and $295 \mathrm{~K}$.

\begin{tabular}{lcccccccc}
\hline $\begin{array}{l}\mathbf{C}_{\mathbf{0}} \\
(\mathbf{m g} / \mathbf{L})\end{array}$ & $\begin{array}{c}\mathbf{Z} \\
(\mathbf{c m})\end{array}$ & $\begin{array}{c}\mathbf{Q} \\
(\mathbf{m L} / \mathbf{m i n})\end{array}$ & $\begin{array}{c}\mathbf{t}_{\mathbf{b}} \\
(\mathbf{m i n})\end{array}$ & $\begin{array}{c}\mathbf{t}_{\mathbf{s}} \\
(\mathbf{m i n})\end{array}$ & $\begin{array}{c}\mathbf{q}_{\mathbf{e}} \\
(\mathbf{m g} / \mathbf{g})\end{array}$ & $\begin{array}{c}\mathbf{R} \\
(\mathbf{\%})\end{array}$ & $\begin{array}{c}\mathbf{V}_{\mathbf{b}} \\
(\mathbf{m L})\end{array}$ & $\begin{array}{c}\mathbf{V}_{\mathbf{s}} \\
(\mathbf{m L})\end{array}$ \\
\hline 50 & 10 & 2 & 18 & 210 & 0.5 & 18.7 & 36 & 420 \\
100 & 10 & 2 & - & 270 & 1.5 & 18.2 & - & 540 \\
100 & 20 & 2 & 20 & 420 & 1.4 & 25.4 & 200 & 840 \\
100 & 10 & 4 & - & 270 & 2.2 & 13.2 & - & 1,080 \\
\hline
\end{tabular}

fixed-bed column, $\mathrm{R}$ is the removal (\%) of $\mathrm{Pb}(\mathrm{II}), \mathrm{q}_{\mathrm{m}}(\mathrm{mg} / \mathrm{g})$ is the maximum monolayer adsorption capacity, $\mathrm{V}_{\mathrm{b}}$ and $\mathrm{V}_{\mathrm{s}}(\mathrm{mL})$ is the amount of solution until breakthrough time and exhaustion time, respectively. $\mathrm{t}_{\mathrm{b}}$ and $\mathrm{t}_{\mathrm{s}}(\mathrm{min})$ is the breakthrough time $\left(\mathrm{C}_{\mathrm{t}} / \mathrm{C}_{0}\right.$ $=0.05)$ and exhaustion time $\left(\mathrm{C}_{\mathrm{t}} / \mathrm{C}_{0}=0.95\right)$, respectively, and $\mathrm{Q}$ is the volumetric flow rate $(\mathrm{mL} / \mathrm{min})$.

\section{Effect of Flow Rate}

Among the various operating factors, which affect the efficiency of a fixed-bed column, the flow rate plays an important role since it directly relates to the contact time between the adsorbent and adsorbate in the column, which also affects the resistance to the mass transfer (Ahmed and Hameed, 2018). In order to study the effect of flow rate on the adsorption of lead in fixed-bed column, two different flow rates at 2 and $4 \mathrm{~mL} / \mathrm{min}$ were studied. Other parameters such as bed height, initial $\mathrm{Pb}$ (II) concentration, and $\mathrm{pH}$ of the lead nitrate solution were held constant at $10 \mathrm{~cm}, 100$ $\mathrm{mg} / \mathrm{L}$, and $\mathrm{pH} 6.5$, respectively. The breakthrough curves for different flow rates and the parameters of dynamic adsorption are presented in the Figures $\mathbf{7 A - C}$ and Table 3. It is noted that the rate of adsorption for both flow rates are fast at the beginning of the process and reach a plateau value of $2 \mathrm{~mL} / \mathrm{min}$ at $150 \mathrm{~min}$. By comparison, the use of a $4 \mathrm{~mL} / \mathrm{min}$ flow rate yielded a significant decrease to $50 \mathrm{~min}$. The breakthrough time for both flow rates occur before the first sample was collected, where the exhaustion time for both flow rates are equal $(270 \mathrm{~min})$. Overall, a significant change was not observed in the behavior of breakthrough curves at a flow rate of $2 \mathrm{~mL} / \mathrm{min}$ and $4 \mathrm{~mL} / \mathrm{min}$, except in the region between 50 and $100 \mathrm{~min}$. This trend occurs when the ratio of 
$\mathrm{C}_{\mathrm{t}} / \mathrm{C}_{0}$ for a flow rate of $2 \mathrm{~mL} / \mathrm{min}$ is lower than that observed for $4 \mathrm{~mL} / \mathrm{min}$. This implies that more $\mathrm{Pb}$ (II) ions were adsorbed by the adsorbent in this region. Various column studies for the adsorption of lead cations with different adsorbents have been reported (Bulgariu and Bulgariu, 2013; Sabourian et al., 2016; Bai and Venkateswarlu, 2018; Basu et al., 2019). In general, as the flow rate in fixed-bed column increased, the breakthrough time and exhaustion time decreased, where the breakthrough curves for higher flow rate reach the saturation point more rapidly (Han et al., 2006). Furthermore, as the flow rate increases from 2 to 4 $\mathrm{mL} / \mathrm{min}$, the maximum adsorption capacity increased from 1.5 to $2.2 \mathrm{mg} / \mathrm{g}$. This may be related to the role of higher flow rate, where greater levels of $\mathrm{Pb}$ (II) ions likely pass through the column, as compared to lower flow rates. In turn, the use of lower flow rate led to an increase in the maximum adsorption capacity.

\section{Effect of Lead Concentration}

The initial concentration of a heavy metal has a significant effect on the behavior of the breakthrough curves in a dynamic adsorption process since the concentration provides a driving force to transfer the ions onto the active surface sites of the adsorbent. Herein, the effect of $\mathrm{Pb}$ (II) concentration on the adsorption process was studied in a dynamic system. Two different $\mathrm{Pb}(\mathrm{II})$ concentrations (50 and $100 \mathrm{mg} / \mathrm{L}$ ) at constant flow rate of $2 \mathrm{~mL} / \mathrm{min}$ were tested with a fixed bed height of $10 \mathrm{~cm}$. As depicted in Figure 7B, the breakthrough shifted to the left when the concentration of $\mathrm{Pb}$ (II) was $50 \mathrm{mg} / \mathrm{L}$. As compared with the $100 \mathrm{mg} / \mathrm{L} \mathrm{Pb}(\mathrm{II})$ concentration, this shift is negligible for the initial part of the breakthrough curve. This trend may relate to the limited number of active sites on the surface of the adsorbent pellet, which can be occupied rapidly by the $\mathrm{Pb}$ (II) ions. The breakthrough curves showed that as the initial $\mathrm{Pb}$ (II) concentration is $100 \mathrm{mg} / \mathrm{L}$, the ratio of $\mathrm{C}_{\mathrm{t}} / \mathrm{C}_{0}$ is lower than the $50 \mathrm{mg} / \mathrm{L}$ for $\mathrm{Pb}(\mathrm{II})$, relating to the higher driving force at elevated initial concentration of $\mathrm{Pb}(\mathrm{II})$. According to Table 3, the breakthrough time for the initial $\mathrm{Pb}$ (II) concentration at 50 $\mathrm{mg} / \mathrm{L}$ is $20 \mathrm{~min}$ and the exhaustion time is $210 \mathrm{~min}$. Also, the exhaustion time for $100 \mathrm{mg} / \mathrm{L} \mathrm{Pb}$ (II) is $270 \mathrm{~min}$, whereas the breakthrough time could not be measured since the ratio of $\mathrm{C}_{t} / \mathrm{C}_{0}$ for the first sample was higher than 0.05. Various studies have shown (Ji et al., 2013; Shabtai et al., 2021) that as the initial concentration of contaminants increase, the breakthrough time and exhaustion time undergoes a decrease. Herein, an opposite trend is reported, which may relate to the porosity of the material and the driving force that occurs for elevated $\mathrm{Pb}$ (II) levels. Moreover, as the concentration of $\mathrm{Pb}$ (II) increased from 50 to $100 \mathrm{mg} / \mathrm{L}$, the value of $\mathrm{q}_{\mathrm{m}}$ increased from 0.5 to $1.5 \mathrm{mg} / \mathrm{g}$, in agreement with the estimated value of $\mathrm{Q}_{\mathrm{m}}$ from the batch study (cf. Table 2). This observation relates to the greater driving force at elevated levels of $\mathrm{Pb}$ (II) species (Masukume et al., 2011).

\section{Effect of Bed Height}

The amount of adsorbent that can be packed within the column directly affects the parameters of the breakthrough curves: breakthrough time $\left(t_{b}\right)$, exhaustion time $\left(t_{s}\right)$ and the adsorption capacity $\left(\mathrm{q}_{\mathrm{m}}\right)$. It can be understood that the amount of adsorbent provides sufficient active sites on the surface for $\mathrm{Pb}(\mathrm{II})$ ions in the influent solution. Herein two different bed heights of
10 and $20 \mathrm{~cm}$ were investigated, while the other operating parameters such as $\mathrm{pH}(6.5)$, flow rate $(4 \mathrm{~mL} / \mathrm{min})$, and the initial lead concentration $(100 \mathrm{mg} / \mathrm{L})$ was held constant. As noted in Figure $7 \mathrm{C}$, the breakthrough curves shifted to the origin and the adsorbent reaches saturation more rapidly as the bed height decreases from 20 to $10 \mathrm{~cm}$. This phenomenon relates to trend of the increased bed height, where more active sites are available for $\mathrm{Pb}(\mathrm{II})$ ions to bind with the adsorbent. Hence, the time required to reach the saturation point increases (Basu et al., 2019). Similar observations were reported for the adsorption of lead onto Auricularia matrix waste (Qu et al., 2019). The breakthrough time for $20 \mathrm{~cm}$ bed height is $20 \mathrm{~min}$, whereas it was not measurable for a $10 \mathrm{~cm}$ bed height since the ratio of $\mathrm{C}_{\mathrm{t}} / \mathrm{C}_{0}$ for the first sample at the outlet exceeds 0.05. Moreover, the exhaustion point increased from 270 to $420 \mathrm{~min}$ when the bed height increased from 10 to $20 \mathrm{~cm}$.

\section{CONCLUSIONS}

This study reports on the preparation and characterization of several binary and ternary composite pellet materials that contain chitosan (CP), kaolinite and agro-waste biomass (wheat straw or oat hulls) at variable composition (cf. Table 1). The spectral (NMR, IR) characterization and thermal analysis results provide complementary support for the adsorbent characterization and the role of non-covalent stabilization effects among the pelletized components. The batch adsorption results for lead nitrate at $\mathrm{pH}$ 6.5 and $295 \mathrm{~K}$ reveal that such composites with greater agro-waste biomass fractions displayed greater adsorption on account of the lignocellulosic contributions due to the role of ion-exchange sites for $\mathrm{Pb}(\mathrm{II})$. The optimal ternary composite containing the oat hulls (CPKO40) had the following composition: chitosan (50 wt.\%) + kaolinite (10 wt.\%) + oat hulls (40 wt.\%), where oat hulls and bentonite contribute to a negative surface charge of the adsorbent at $\mathrm{pH}$ 6.5. The monolayer adsorption capacity $\left(\mathrm{Q}_{\mathrm{m}}\right)$ of $\mathrm{CPKO} 40$ with $\mathrm{Pb}(\mathrm{II})$ had the highest $\mathrm{Pb}(\mathrm{II})$ adsorption capacity $(1,910 \mu \mathrm{g} / \mathrm{g})$ in batch mode. The primary adsorption site serves as ion-exchange for $\mathrm{Pb}(\mathrm{II})$, which was attributed to the lignin fraction of the agro-waste biomass due to ionization of the phenolic sites and negative surface charge of the adsorbent at $\mathrm{pH}$ 6.5. The abundant $-\mathrm{OH}$ groups of the polysaccharide fraction (chitosan and (hemi)celluloses) were assigned as the secondary sites due to the role of electrostatic interactions with $\mathrm{Pb}$ (II) (cf. Figure 6). A dynamic column adsorption study was carried out using a fixed-bed CPKO40 system to analyze the breakthrough time dependence for the $\mathrm{Pb}(\mathrm{II})$ species, where greater influent concentration and flow rate led to shorter breakthrough times, while greater bed height led to longer breakthrough times. Convergent uptake results for $\mathrm{Pb}$ (II) by the $\mathrm{CPKO} 40$ adsorbent (cf. Tables 2, 3) were demonstrated for the batch mode and results from the fixed-bed column study herein. CPKO40 was shown to be a sustainable adsorbent material for the controlled removal of $\mathrm{Pb}$ (II) ions, especially for POU water treatment. The valorization of low-cost agro-waste biomass, such as oat hulls, was demonstrated by a 5-fold enhancement of the $\mathrm{Q}_{\mathrm{m}}$ value for $\mathrm{CPKO} 40$ with $\mathrm{Pb}(\mathrm{II})$, as compared with pristine chitosan pellet systems. The incorporation of oat hulls up to $40 \mathrm{wt}$.\% was achieved without covalent modification to 
yield stable ternary composite adsorbents in aqueous media at $\mathrm{pH}$ 6.5. Further studies are underway to investigate the removal properties of diverse waterborne contaminants using such types of pelletized biocomposite adsorbent technology to address global water security issues for the controlled removal of contaminants (Shabtai et al., 2021).

\section{DATA AVAILABILITY STATEMENT}

The original contributions presented in the study are included in the article/Supplementary Material, further inquiries can be directed to the corresponding author.

\section{AUTHOR CONTRIBUTIONS}

MM, IU, MS, BS, and ZZ contributed equally to the experimental aspects of work and along with contributions to the draft version of the manuscript. LW supervised the work, acquired the funding for this study completed the first draft, and carried out revisions to the manuscript during the publication process. All authors contributed to the experimental work and approved the submitted version.

\section{FUNDING}

The support provided by the Global Institute for Water Security is gratefully acknowledged for the 2020 GIWS/GWF Capacity Building Competition Award (Grant \#: 418606-1323) to LW to

\section{REFERENCES}

Ahmed, M. J., and Hameed, B. H. (2018). Removal of emerging pharmaceutical contaminants by adsorption in a fixed-bed column: a review, Ecotoxicol. Environ. Saf. 149, 257-266. doi: 10.1016/j.ecoenv.2017.12.012

Alabi, W., Karoyo, A. H., Krishnan, E. N., Dehabadi, L., Wilson, L. D., and Simonson, C. J. (2020). Comparison of the moisture adsorption properties of starch particles and flax fiber coatings for energy wheel applications. ACS Omega 16, 9529-9539. doi: 10.1021/acsomega.0c00762

Anisimov, Y. A., Cree, D. E., and Wilson, L. D. (2020). Preparation of multicomponent biocomposites and characterization of their physicochemical and mechanical properties. J. Compos. Sci. 4:18. doi: 10.3390/jcs401 0018

$\mathrm{Au}, \mathrm{P}$.-I., and Leong, Y.-K. (2016). Surface chemistry and rheology of slurries of kaolinite and montmorillonite from different sources. KONA Powder Part. J. 33, 17-32. doi: 10.14356/kona.2016007

Bai, M. T., and Venkateswarlu, P. (2018). Fixed bed and batch using Sargassum Tenerrimum powder: characterization, thermodynamics. Mater. Today Proc. 5, 18024-18037. doi: 10.1016/j.matpr.2018.06.136

Bailey, S. E., Olin, T. J., Bricka, R. M., and Adrian, D. D. (1999). A review of potentially low-cost sorbents for heavy metals. Water Res. 33, 2469-2479. doi: 10.1016/S0043-1354(98)00475-8

Basu, M., Guha, A. K., and Ray, L. (2019). Adsorption of lead on lentil husk in fixed bed column bioreactor. Bioresour. Technol. 283, 86-95. doi: 10.1016/j.biortech.2019.02.133

Beni, A. A., and Esmaeili, A. (2020). Biosorption, an efficient method for removing heavy metals from industrial effluents: a Review. Environ. Technol. Innovat. 17:10050. doi: 10.1016/j.eti.2019.100503

Boominathan, T., and Sivaramakrishna, A. (2021). Recent advances in the synthesis, properties, and applications of modified chitosan derivatives: challenges and opportunities. Top. Curr. Chem. 379:19. doi: $10.1007 /$ s41061-021-00331-z support the research project entitled, Development of Torrefied Waste Biomass for Remediation and Monitoring of Metal Ions in Aquatic Environments.

\section{ACKNOWLEDGMENTS}

LW acknowledges Tony Chau at Saskatchewan Polytechnic during the initial stages of this work for providing access to the ICP-OES instrumentation to enable preliminary estimates of $\mathrm{Pb}$ (II) levels, and to Valerie MacKenzie at the University of Saskatchewan (USask) for providing access to the Flame Atomic Absorption Spectroscopy instrument to enable quantitative analysis of $\mathrm{Pb}(\mathrm{II})$ levels reported herein. The authors acknowledge Richard Evitts at USask for providing the agro-waste biomass (oat hulls and torrefied wheat straw) used in this research.

\section{SUPPLEMENTARY MATERIAL}

The Supplementary Material for this article can be found online at: https://www.frontiersin.org/articles/10.3389/frwa. 2022.739492/full\#supplementary-material

The materials include IR spectra of the two- and threecomponent composite materials, equilibrium uptake of lead nitrate by single component additives, equilibrium uptake of lead nitrate by the ternary composite (CPKO40) with $\mathrm{Pb}(\mathrm{II})$, and other divalent competitor ions (and their equimolar mixtures), and water quality parameters for the City of Saskatoon tap water.

Bulgariu, D., and Bulgariu, L. (2013). Sorption of $\mathrm{Pb}$ (II) onto a mixture of algae waste biomass and anion exchanger resin in a packed-bed column. Bioresour. Technol. 129, 374-380. doi: 10.1016/j.biortech.2012.10.142

Cheng, H., Liu, Q., Yang, J., Zhang, Q., and Frost, R. L. (2010). Thermal behavior and decomposition of kaolinite-potassium acetate intercalation composite. Thermochim. Acta. 503-504, 16-20. doi: 10.1016/j.tca.2010.02.014

Cribb, R., Cohen, B., Keogh, D., Buckley, C., and Mutis, J. (2019). Is There Lead in Your Tap Water? Canada-Wide Investigation Exposes Dangerous Levels of Toxic Metal. Toronto Star, Nov. 4, (2021). Available online at: https://www.thestar. com/news/investigations/2019/11/04/is-there-lead-in-your-water-canadawide-investigation-exposes-chronic-extreme-exceedances- of-toxic-metal. html (accessed January 12, 2022).

de Franco, M. A. E., Carvalho, C. B., Bonetto, M. M., de Pelegrini Soares, R., and Féris, L. A. (2017). Removal of amoxicillin from water by adsorption onto activated carbon in batch process and fixed bed column: kinetics, isotherms, experimental design and breakthrough curves modelling. J. Clean. Prod. 161, 947-956. doi: 10.1016/j.jclepro.2017.05.197

de Oliveira, J. P., Brunia, G. P., Lima, K. O., El Halala, S. L. M., da Rosa, G. S., Guerra Diasa, A. (2017). Cellulose fibers extracted from rice and oat husks and their application in hydrogel. Food Chem. 221, 153-160. doi: 10.1016/j.foodchem.2016.10.048

Dehabadi, L., Karoyo, A. H., Soleimani, M., Alabi, W. O., Simonson, C. J., and Wilson, L. D. F. (2020). Flax biomass conversion via controlled oxidation: facile tuning of physicochemical properties. Bioengineering 7:38. doi: 10.3390/bioengineering7020038

Elanchezhiyana, S. S. D., Karthikeyan, P., Rathinam, K., Farzana, M. H., and Park, C. M. (2021). Magnetic kaolinite immobilized chitosan beads for the removal of $\mathrm{Pb}(\mathrm{II})$ and $\mathrm{Cd}(\mathrm{II})$ ions from an aqueous environment. Carbohyd. Polym. 261:117892. doi: 10.1016/j.carbpol.2021.117892

Franca, E. F., Lins, R. D., Freitas, L. C. G., and Straatsma, T. P. C. (2008). Characterization of chitin and chitosan molecular structure in aqueous solution. J. Chem. Theory Comput. 4, 2141-2149. doi: 10.1021/ct8002964 
Gao, X., Zhang, H., Chen, K., Zhou, J., and Liu, Q. (2018). Removal of heavy metal and sulfate ions by cellulose derivative-based biosorbents. Cellulose 25, 2531-2545. doi: 10.1007/s10570-018-1690-x

Guo, R., Bharadwaj, L., and Wilson, L. D. (2021). Adsorption studies of waterborne trihalomethanes using modified polysaccharide adsorbents. Molecules 26:1431. doi: 10.3390/molecules26051431

Han, R., Zhang, J., Zou, W., Xiao, H., Shi, J., and Liu, H. (2006). Biosorption of copper(II) and lead(II) from aqueous solution by chaff in a fixed-bed column. J. Hazard. Mater. 133, 262-268. doi: 10.1016/j.jhazmat.2005.10.019

Hanna-Attisha, M., LaChance, J., Sadler, R. C., and Schnepp, A. C. (2016). Elevated blood lead levels in children associated with the flint drinking water crisis: a spatial analysis of risk and public health response. Am. J. Public Health. 106, 283-290. doi: 10.2105/AJPH.2015.303003

Horikawa, Y., Hirano, S., Mihashi, A., Kobayashi, Y., Zhai, S., and Sugiyama, J. (2019). Prediction of lignin contents from infrared spectroscopy: chemical digestion and lignin/biomass ratios of Cryptomeria japonica. Appl. Biochem. Biotechnol. 188, 1066-1076. doi: 10.1007/s12010-019-02965-8

Huang, H. (2016). The Eh-pH diagram and its advances. Metals 6:23. doi: $10.3390 /$ met 6010023

Ji, F., Li, C., Xu, J., and Liu, P. (2013). Dynamic adsorption of Cu(II) from aqueous solution by zeolite/cellulose acetate blend fiber in fixed-bed, Colloids Surfaces A Physicochem. Eng. Asp. 434, 88-94. doi: 10.1016/j.colsurfa.2013.05.045

Kang, X., Kirui, A., Dickwella Widanage, M. C., Mentink-Vigier, F., Cosgrove, D. J., and Wang, T. (2019). Lignin-polysaccharide interactions in plant secondary cell walls revealed by solid-state NMR. Nat. Commun. (2019) 10:347. doi: 10.1038/s41467-018-08252-0

Li, N., and Bai, R. (2005). Copper adsorption on chitosan-cellulose hydrogel beads: behaviors and mechanisms. Separat. Purific. Technol. 42, 237-247. doi: 10.1016/j.seppur.2004.08.002

Ma, C., and Eggleton, R. A. (1999). Cation exchange capacity of kaolinite. Clays Clay Miner. 47, 174-180. doi: 10.1346/CCMN.1999.0470207

Masukume, M., Eskandarpour, A., Onyango, M. S., Ochieng, A., and Otieno, F. (2011). Treating high nitrate groundwater using surfactant modified zeolite in fixed bed column. Sep. Sci. Technol. 46, 1131-1137. doi: 10.1080/01496395.2010.551246

Mohamed, M. H., Peru, K. M., Headley, J. V., and Wilson, L. D. (2017). Chitosan biopolymers for analysis of organic acids in aquatic environments of treatment wetlands. J. Geosci. Environ. Prot. 5, 214-225. doi: 10.4236/gep.2017.56019

Mohamed, M. H., Udoetok, I. A., and Wilson, L. D. (2020). Animal biopolymerplant biomass composites: synergism and improved sorption efficiency. J. Compos. Sci. 4:15. doi: 10.3390/jcs4010015

Mohamed, M. H., and Wilson, L. D. (2015). Kinetic uptake studies of powdered materials in solution. Nanomaterials 5, 969-980. doi: 10.3390/nano5020969

Mudhoo, A., Garg, V. K., and Wang, S. (2012). Removal of heavy metals by biosorption. Environ. Chem. Lett. 10:109-117. doi: 10.1007/s10311-0110342-2

Overah, L., and Ifeanyi, O. (2017). Evaluation of Dacryodes edulis (native pear) seed biomass for $\mathrm{Pb}(\mathrm{II})$ sorption from aqueous solution. J. Appl. Sci. Environ. Manag. 21, 186-199. doi: 10.4314/jasem.v21i1.19

Pandey, L. M. S. (2020). Surface engineering of nano-sorbents for the removal of heavy metals: interfacial aspects. J. Environ. Chem. Eng. 9:104586. doi: $10.1016 /$ j.jece. 2020.104586

Patel, H. (2019). Fixed-bed column adsorption study: a comprehensive review. Appl. Water Sci. 9:45. doi: 10.1007/s13201-019-0927-7

Powell, K. J., Brown, P. L., Byrne, R. H., Gajda, T., Hefter, G., Leuz, A., et al. (2009). Chemical speciation of environmentally significant metals with inorganic ligands. Part 3: the $\mathrm{Pb}^{2+}+\mathrm{OH}^{-}, \mathrm{Cl}^{-}, \mathrm{CO}^{32-}, \mathrm{SO}^{42-}$, and $\mathrm{PO}^{43-}$ systems (IUPAC Technical Report). Pure Appl. Chem. 81, 2425-76. doi: 10.1351/PAC-REP-09-03-05

Qu, J., Song, T., Liang, J., Bai, X., Li, Y., Wei, Y., et al. (2019). Adsorption of lead (II) from aqueous solution by modified Auricularia matrix waste: a fixed-bed column study. Ecotoxicol. Environ. Saf. 169, 722-729. doi: 10.1016/j.ecoenv.2018.11.085

Ragnar, M., Lindgren, C. T., and Nilvebrant, N.-O. (2000). pKa -values of Guaiacyl and syringyl phenols related to lignin. J. Wood Chem. Technol. 20, 277-305. doi: 10.1080/02773810009349637

Sabourian, V., Ebrahimi, A., Naseri, F., Irani, M., and Rahimi, A. (2016). Fabrication of chitosan/silica nanofibrous adsorbent functionalized with amine groups for the removal of $\mathrm{Ni}$ (II), $\mathrm{Cu}$ (II) and $\mathrm{Pb}$ (II) from aqueous solutions: batch and column studies. RSC Adv. 6, 40354-40365. doi: 10.1039/C6RA00456C

Sabzevari, M., Cree, D. E., and Wilson, L. D. G. (2018). Oxide-chitosan composite material for treatment of a model dye effluent. ACS Omega 3, 13045-13054. doi: 10.1021/acsomega.8b01871

Sajjadi, M., Ahmadpoor, F., Nasrollahzadeh, M., and Ghafuri, H. (2021). Ligninderived (nano)materials for environmental pollution remediation: current challenges and future perspectives. Int. J. Biol. Macromol. 178, 394-423. doi: 10.1016/j.ijbiomac.2021.02.165

Santucci Jr, R. J., and Scully, J. R. (2020). The pervasive threat of lead (Pb) in drinking water: Unmasking and pursuing scientific factors that govern lead release. PNAS. 117, 23211-18. doi: 10.1073/pnas.1913749117

Shabtai, I. A., Lynch, L. M., and Mishael, Y. G. D. (2021). clay-polymer nanocomposite sorbents for water treatment: a review and meta-analysis of the past decade. Water Res. 188:116571. doi: 10.1016/j.watres.2020.116571

Shakoor, M. B., Ali, S., Rizwan, M., Abbas, F., Bibi, I., Riaz, M., et al. (2020). A review of biochar-based sorbents for separation of heavy metals from water. Int. J. Phytoremed. 22, 111-126. doi: 10.1080/15226514.2019.1647405

Shareef, K. M. (2009). Sorbents for contaminants uptake from aqueous solutions. Part I: heavy metals. World J. Agricul. Sci. 5(S), 819-831.

Sips, R. (1948). Structure of a catalyst surface. J. Chem. Phys. 16, 490-495. doi: 10.1063/1.1746922

Solgi, M., Tabil, L. G., and Wilson, L. D. M. (2020). Modified biopolymer adsorbents for column treatment of sulfate species in saline aquifers. Materials 13:2408. doi: 10.3390/ma13102408

Syauqiah, I., Kurnain, A., Masrevaniah, A., and Kusuma, Z. (2015). Pellets' pore characteristics on the fly ash-chitosan composite crosslinked to glutaraldehyde. Int. J. ChemTech Res. 7, 2071-2076.

Torrice, M. (2016). How lead ended up in flint's tap water. Chem. Eng. News. 94:09407. doi: 10.1021/cen-09407-scitech1

Udoetok, I. A., Wilson, L. D., and Headley, J. V. S. (2016). Self-assembled and cross-linked animal and plant-based polysaccharides: chitosan-cellulose composites and their anion uptake properties. ACS Appl. Mater. Interfaces 8, 33197-33209. doi: 10.1021/acsami.6b11504

Vafakish, B., and Wilson, L. D. (2020). Cu(II) adsorption by aniline grafted chitosan and its responsive fluorescence properties. Molecules 25:1052. doi: 10.3390/molecules25051052

Wilson, K., and Ackerman, J. (2019). Saskatchewan Residents Have Some of Highest Levels of Lead-Tainted Water in Canada. Global News, November 4. Available online at: https://globalnews.ca/news/6120813/saskatchewan-leadtainted-water/ (accessed January 12, 2022).

Wilson, L. D., and Tewari, B. B. (2018). Chitosan-based adsorbents: environmental applications for the removal of arsenicals, chapter 7, In Chitosan-Based Adsorbents for Wastewater Treatment (Ed. Abu Nasar). Mat. Res. Forum LLC Mat. Res. Found. 34, 133-160. doi: 10.21741/9781945291753-7

Zawadzki, J., and Kaczmarek, H. (2010). Thermal treatment of chitosan in various conditions. Carbohyd. Polym. 80, 394-400. doi: 10.1016/j.carbpol.2009.11.037

Zhou, Y., and Haynes, R. J. (2010). Sorption of heavy metals by inorganic and organic components of solid wastes: significance to use of wastes as lowcost adsorbents and immobilizing agents. Crit. Rev. Environ. Sci. Technol. 40:909-977. doi: 10.1002/chin.201145275

Conflict of Interest: The authors declare that the research was conducted in the absence of any commercial or financial relationships that could be construed as a potential conflict of interest.

Publisher's Note: All claims expressed in this article are solely those of the authors and do not necessarily represent those of their affiliated organizations, or those of the publisher, the editors and the reviewers. Any product that may be evaluated in this article, or claim that may be made by its manufacturer, is not guaranteed or endorsed by the publisher.

Copyright (c) 2022 Mohamed, Udoetok, Solgi, Steiger, Zhou and Wilson. This is an open-access article distributed under the terms of the Creative Commons Attribution License (CC BY). The use, distribution or reproduction in other forums is permitted, provided the original author(s) and the copyright owner(s) are credited and that the original publication in this journal is cited, in accordance with accepted academic practice. No use, distribution or reproduction is permitted which does not comply with these terms. 